\title{
Evaluation of subclinical cardiac damage in biopsy-proven nonalcoholic fatty liver disease: a systematic review and meta-analysis
}

\author{
Artemis Christina Oikonomidou a, loannis Doundoulakis ${ }^{\mathrm{a}, \mathrm{b}}$, Christina Antzac, Georgios Kalopitas ${ }^{\mathrm{d}}$, \\ Theodoros Dardavessis ${ }^{a}$, Michail Chourdakis ${ }^{a}$
}

Aristotle University of Thesalloniki; G.H. Papageorgiou, Aristotle University of Thessaloniki; AHEPA University Hospital, School of Medicine, Aristotle University of Thessaloniki, Greece

\section{Abstract}

Background Data on the association of nonalcoholic fatty liver disease (NAFLD) with subclinical cardiac damage are scanty. We performed a systematic review to provide comprehensive information on subclinical cardiac alterations among NAFLD subjects.

Methods PubMed and the Cochrane Library were searched to identify studies comparing subclinical cardiac damage between NAFLD and healthy adults. We also searched PROSPERO to check for any similar meta-analysis in progress in order to avoid duplication with our study. Conference abstracts and the reference lists of relevant studies and systematic reviews were perused. The NewcastleOttawa quality assessment scale for case-control and cohort studies were used to assess study quality.

Results Seven studies were finally included in the meta-analysis ( 1 cross sectional and 6 casecontrol), with a total of 602 individuals (362 patients with NAFLD). Epicardial fat thickness were statistically significantly higher in patients with NAFLD than in controls (mean difference [MD] 1.17, 95\% confidence interval [CI] $0.45-1.89, I^{2}=89 \%$ ). Global longitudinal strain was lower in NAFLD, to a statistically significant degree (MD $-3.17,95 \%$ CI -5.09 to $-1.24, I^{2}=89 \%$ ). However, significant heterogeneity of the findings was observed.

Conclusions Our findings indicate that NAFLD is related to subclinical cardiac damage. Further studies with a larger number of biopsy-proven NAFLD patients are needed to confirm this finding. Preventive and therapeutic interventions early in the course of the disease might decrease morbidity in this high-risk patient group.

Keywords Nonalcoholic fatty liver disease, epicardial fat thickness, global longitudinal strain, liver biopsy

Ann Gastroenterol 2021; 35 (1): 1-7

\section{Introduction}

Nonalcoholic fatty liver disease (NAFLD) is a modern epidemic that affects more than $25 \%$ of the general population

${ }^{a}$ Department of Hygiene, Social \& Preventive Medicine and Medical Statistics, School of Medicine, Faculty of Health Sciences, Aristotle University of Thessaloniki, Thessaloniki (Artemis Christina Oikonomidou, Ioannis Doundoulakis, Theodoros Dardavessis, Michail Chourdakis); bepartment of Cardiology, 424 General Military Training Hospital, Thessaloniki (Ioannis Doundoulakis); ' $3^{\text {rd }}$ Department of Internal Medicine, G.H. "Papageorgiou", School of Medicine, Faculty of Health Sciences, Aristotle University of Thessaloniki (Christina Antza); ${ }^{\mathrm{D} D i v i s i o n}$ of Gastroenterology and Hepatology, $1^{\text {st }}$ Department of Internal Medicine, AHEPA University Hospital, School of Medicine, Faculty of Health Sciences, Aristotle University of Thessaloniki (Georgios Kalopitas), Greece

Conflict of Interest: None

Correspondence to: Michail Chourdakis, Associate. Professor of Medical Nutrition, School of Medicine, Faculty of Health Sciences, Aristotle University, University Campus, 54124, Thessaloniki, Greece, e-mail: mhourd@gapps.auth.gr

Received 6 May 2020; accepted 20 October 2020; published online 5 February 2021

DOI: https://doi.org/10.20524/aog.2021.0594 worldwide $[1,2]$. Its prevalence is rising in parallel with obesity, insulin resistance and type 2 diabetes mellitus (T2DM), and it is considered to be the hepatic component of the metabolic syndrome (MetS) [3].

NAFLD is an umbrella term that encompasses nonalcoholic fatty liver, nonalcoholic steatohepatitis (NASH) with or without liver fibrosis, liver cirrhosis and hepatocellular cancer [4]. It is characterized by the presence of steatosis in more than $5 \%$ of the liver in the absence of significant alcohol consumption or other liver diseases [5]. Although the NAFLD diagnosis can be established by ultrasound or other radiological methods, liver biopsy is considered to be the diagnostic gold standard [4].

Notably, cardiovascular disease (CVD) is the most common cause of morbidity and mortality in NAFLD patients [5]. A longterm study conducted by Söderberg et al showed that patients with NAFLD, and biopsy-proven NASH patients in particular, show greater mortality due to CVD [6]. In addition to an increased incidence of coronary artery disease (CAD) and generally symptomatic cardiac disease, NAFLD is believed to contribute to subclinical cardiac damage, even in the early stages of NAFLD. Recently, clinical studies have focused on establishing a potential connection between subclinical cardiac damage markers and 
NAFLD [7]. Additional findings indicate that NAFLD patients may develop carotid intima-media thickening and carotid plaque [8].

Left ventricular mass index and prevalence of left ventricular hypertrophy are quite frequently used to assess the risk of CVD $[9,10]$. These noninvasive and inexpensive markers have been proven effective in discovering cardiovascular deficiencies [11]. Epicardial fat tissue (EFT) thickness has also been proposed as a CVD risk predictor. EFT is an ectopic fat deposition and is located between the myocardium and the visceral layer of the serous pericardium. Its thickness is positively correlated with the amount of visceral adipose tissue $[12,13]$. EFT produces adipocytokines and various other inflammatory molecules and, because of its adjacency to the myocardium and their common microcirculation, it exerts direct harmful effects on the myocardium and the coronary vessels [14]. Thickening of this tissue is correlated with left ventricular dysfunction, CAD and cardiac arrhythmia development [15]. Global longitudinal strain (GLS) is used to calculate the change in myocardial length between end-diastole and end-systole and can identify abnormalities in left ventricular (LV) systoles [16]. Finally, the ratio between early- and late-diastolic mitral inflow velocities (mitral E/A ratio) can be utilized to identify functional alterations of the heart, i.e., to detect any LV diastolic dysfunction [16]. The markers mentioned above have been tested in clinical trials that examined the connection between NAFLD and subclinical cardiac damage, but their results remain contradictory $[9,10,17-19]$.

The aim of this study was to systematically review the literature and to conduct a meta-analysis in order to identify the association of the abovementioned measures of subclinical cardiac alterations with biopsy-proven NAFLD.

\section{Materials and methods}

This systematic review and meta-analysis followed the Preferred Reporting Items for Systematic reviews and Meta-Analyses (PRISMA) statement [20]. All research was performed based on the registered protocol (Registration number: DOI 10.17605/OSF. IO/9JHM5, review protocol available at https://osf.io/9jhm5/).

\section{Data sources}

Search for studies was performed in PubMed (MEDLINE) and Cochrane Library (CENTRAL) databases as well as in "grey literature" sources without language restrictions. The search was conducted with specific wording, as can be found in Supplementary Material 1, from inception up to April $9^{\text {th }}, 2018$, and was updated on April $9^{\text {th }}, 2020$. PROSPERO was also checked to identify possible similar meta-analysis in progress in order to avoid duplication with our study. Finally, we also searched reference lists of relevant reviews, and the annual meeting abstract books of the european atherosclerosis society from 2011 to 2020.

\section{Study selection}

This study included explicitly case-control and cross-sectional studies that reported any subclinical cardiac alteration in biopsy- proven NAFLD patients in comparison to healthy individuals. The studies under consideration included adult populations and the examined key outcomes of cardiac alteration were EFT, mitral E/A ratio, left ventricular ejection fraction (LVEF) and/ or GLS. In addition, 6 of 7 studies in our meta-analysis excluded NAFLD patients with CVD risk factors, including among others hypertension, dyslipidemia and T2DM. Subsequently, our study excluded projects that met the following criteria: 1) non-case control studies; 2) studies with less than 10 individuals in any arm; and 3) juvenile subjects aged below 18 years.

\section{Data extraction}

The MOOSE (Meta-analysis Of Observational Studies in Epidemiology) guidelines were followed in this study for the systematic review (Supplementary Material 2). Initially, the output of our results was inputted to a reference database (EndNote X7 for Windows, Thomson Reuters) and duplicates were removed. Then all titles and abstracts were examined for relevance by 2 researchers (AO and ID). Finally, all relevant studies were examined to ensure that they were eligible for inclusion and a third reviewer (CA) was consulted when any doubts emerged. For all studies, sample size, publication year, age of patients with NAFLD and controls, and percentage of male participants were obtained if applicable. Potential confounders that might affect the risk of increasing left ventricular mass based on biological plausibility were also extracted.

\section{Quality assessment}

The Newcastle-Ottawa Scale (NOS) quality assessment instrument for case-control and cross-sectional studies was used for the risk of bias assessment [21]. Any misalignment was resolved via consensus or by consulting a third researcher.

\section{Statistical analysis}

The random-effects model was applied for the meta-analysis as high heterogeneity was expected among the studies with regard to study populations and diagnostic procedures. The presence of between-study heterogeneity was quantitatively reflected with the $\mathrm{I}^{2}$ index, considering values $>50 \%$ indicative of high heterogeneity. An $I^{2}$ between 30 and $60 \%$ was described as moderate. The effect sizes as mean differences (MD) and their 95\% confidence intervals $(\mathrm{CI})$ were reported when the measures of EFT, GLS, LVEF, and E/A ratio were expressed as means.

\section{Results}

\section{Characteristics and results of the literature search}

Our search initially retrieved 295 studies. Only 7 studies met the inclusion criteria and could be included in our meta-analysis (Fig. 1). The total population of our meta-analysis was 602 
individuals, including 362 in the intervention arm (mean age 44.2 years) and 240 in the control population (mean age 42.9 years). The sample size of each study ranged between 56 and 150 and males made up $49.8 \%$. Of the 362 NAFLD patients, 36 had been diagnosed with MetS, but the remainder did not show any CVD risk factors such as hypertension, dyslipidemia and T2DM. Regarding the outcome measured in each study, 3 studies measured EFT [22-24], 3 measured GLS [16,25,26], 5 LVEF [16,17,23,25,26], and 4 the E/A ratio $[16,17,25,26]$. The characteristics of the 7 studies included in our meta-analysis are shown in Table 1 . The NOS assessment was used for all studies and is presented in Table 2.

\section{Meta-analysis}

\section{EFT}

Of the 7 studies, 3 reported EFT (211 patients with NAFLD and 136 controls) [22-24]. It was observed that the EFT values in patients with NAFLD were significantly higher than in the control group. Specifically, the EFT values in NAFLD patients were between 3.2 and $6.4 \mathrm{~mm}$, whereas among healthy participants the values ranged from $2.6-5.4 \mathrm{~mm}$. The results show a significant $\mathrm{MD}$ in EFT levels between patients and controls (MD 1.17, 95\%CI 0.45-1.89; $\mathrm{P}<0.001$ ). However, significant heterogeneity of the findings $\left(I^{2}=89 \%\right)$ was observed (Fig. 2A).

\section{GLS}

The 3 studies reporting GLS $[16,25,26]$ included 67 patients with NAFLD and 79 controls. A significantly lower mean GLS in NAFLD patients than in controls was observed across all 3 studies. In particular, the mean GLS in patients was between $17 \%$ and $19.3 \%$, while in healthy subjects the range was $19.8-23.7 \%$. The analysis of the results showed that controls had significantly greater GLS compared to patients (MD -3.17, 95\%CI -5.09 to -1.24; $\mathrm{P}<0.001)$, with significant heterogeneity $\left(I^{2}=89 \%\right)$ (Fig. $\left.2 \mathrm{~B}\right)$.

\section{Mitral E/A ratio}

Four studies reported E/A ratios (105 patients with NAFLD and 104 controls) $[16,17,25,26]$. The mean E/A ratio in the NAFLD group was between 0.9 and 1.1, while the controls scored from 1-1.8. The analysis of the results showed that

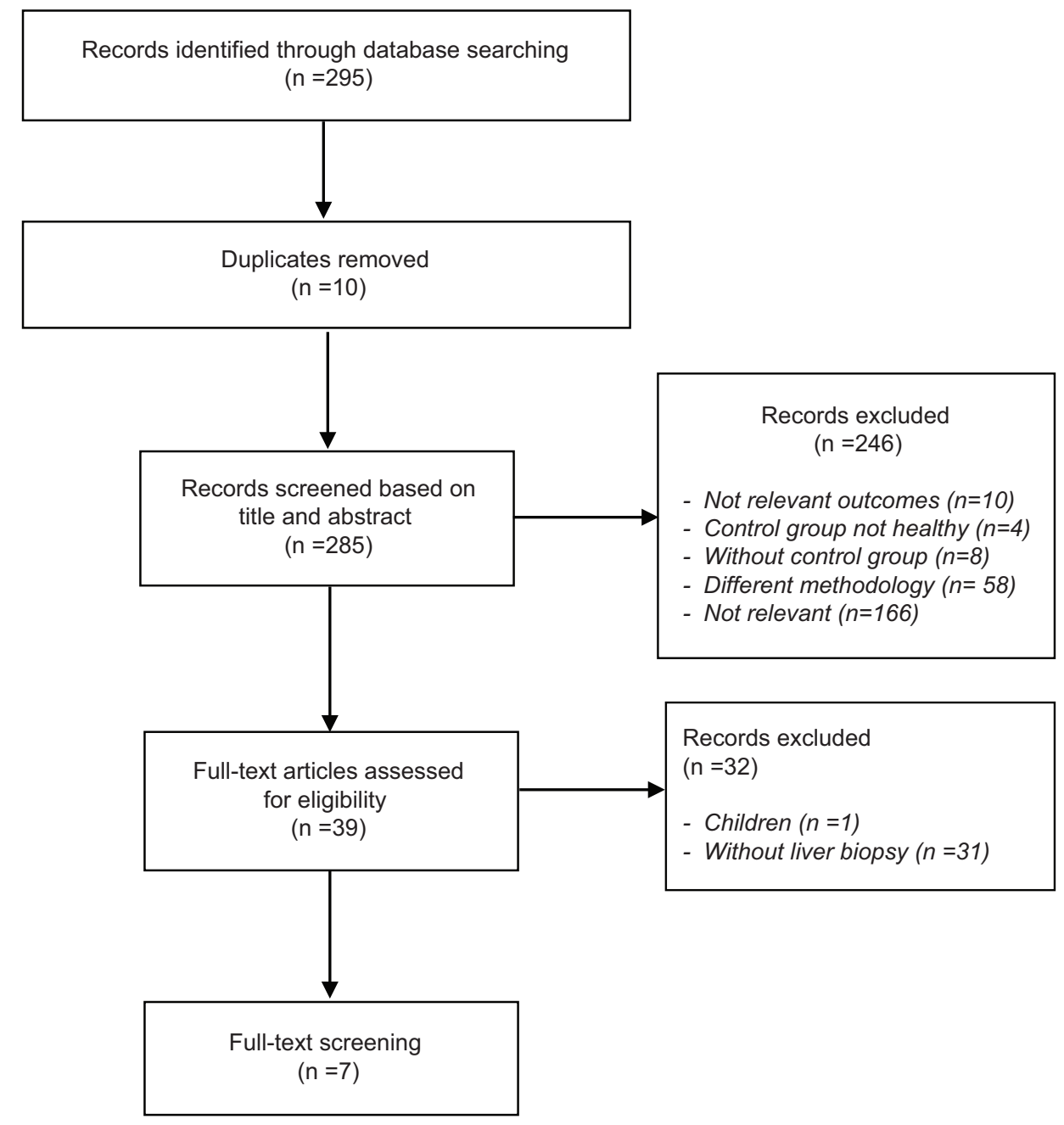

Figure 1 Summary of evidence search and selection 


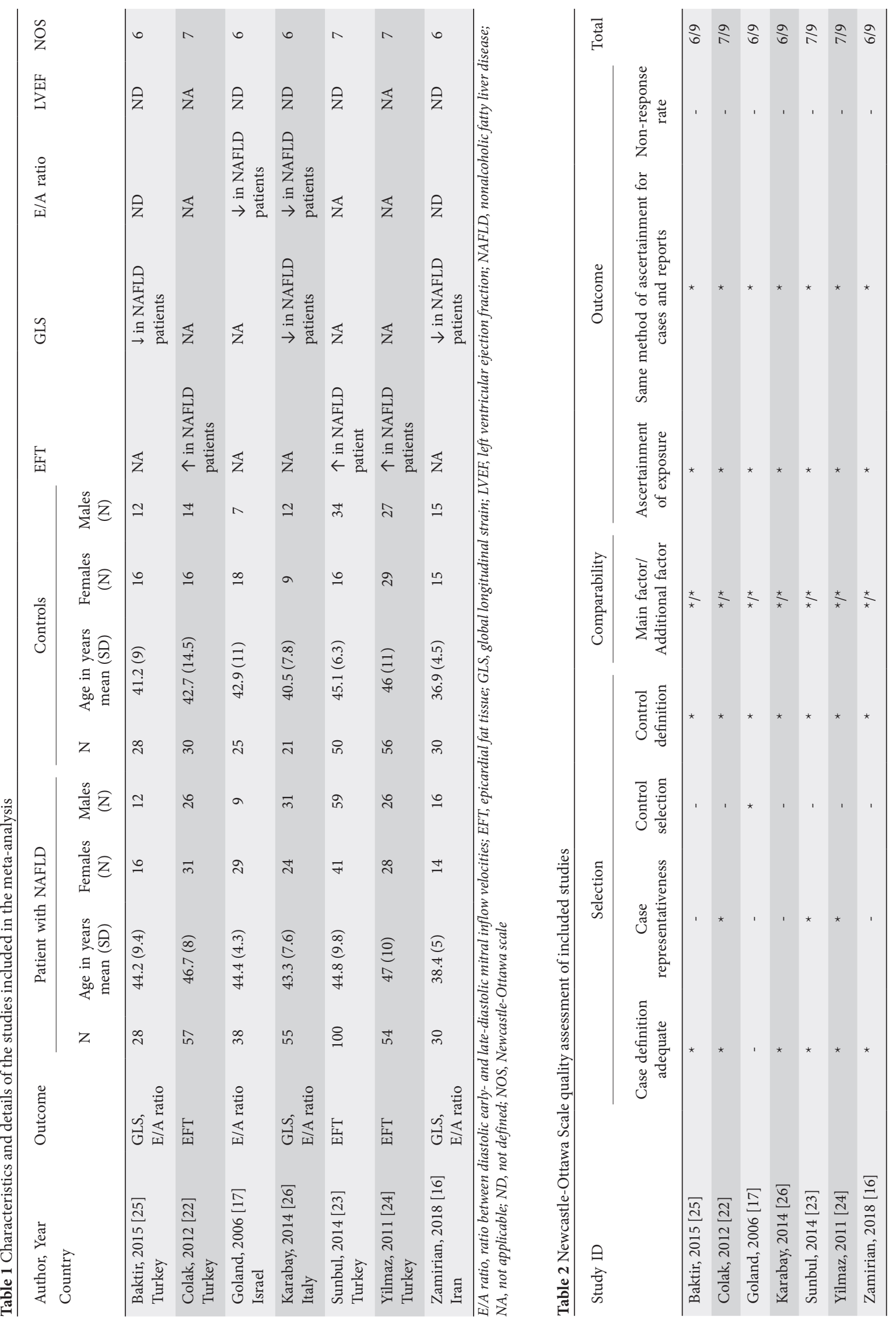


controls had significantly greater values for $\mathrm{E} / \mathrm{A}$ ratio compared to patients (MD $-0.30,95 \% \mathrm{CI}-0.55$ to $-0.04, \mathrm{P}=0.001)$ with significant heterogeneity $\left(I^{2}=81 \%\right)$ (Fig. 2C).

\section{LVEF}

Among the 5 studies that compared LVEF levels (205 NAFLD patients against 154 controls) [16,17,23,25,26], no significant differences were observed (MD -0.50, 95\%CI - 1.63 to $0.64 ; \mathrm{P}=0.39)$, with no significant heterogeneity $\left(I^{2}=0 \%\right)$ (Fig. 2D). The reported mean of LVEF ranged between 56.7 and 66.7 in the NAFLD group, and 57.1 and 66.8 in the controls.

\section{Discussion}

The present systematic review and meta-analysis examined the existence of subclinical cardiac damage in biopsy-proven NAFLD patients. Seven studies [16,17,22-26] with a total number of 602 individuals were included in our meta-analysis. The results showed that people with biopsy-proven NAFLD had a statistically significantly lower E/A ratio and GLS, and significantly higher EFT levels in comparison to healthy controls, while $90 \%$ of them did not show clinical signs of CVD [5,27].

We found that patients with NAFLD had reduced GLS, despite still having a normal LVEF, illustrating that the use of

A

\begin{tabular}{|c|c|c|c|c|c|c|c|c|c|c|c|}
\hline \multirow[b]{2}{*}{ Study or Subgroup } & \multicolumn{2}{|c|}{ NAFLD } & \multicolumn{4}{|c|}{ Control } & \multirow{2}{*}{\multicolumn{2}{|c|}{$\begin{array}{c}\text { Mean Difference } \\
\text { Weight IV, Random, } 95 \% \mathrm{Cl}\end{array}$}} & \multirow{2}{*}{\multicolumn{2}{|c|}{$\begin{array}{c}\text { Mean Difference } \\
\text { IV, Random, } 95 \% \mathrm{Cl}\end{array}$}} & \\
\hline & Mean & SD & Total & Mean & SD & Total & & & & & \\
\hline Colak 2012 & 5.8 & 1.8 & 57 & 3.6 & 1.7 & 30 & $27.1 \%$ & $2.20[1.43,2.97]$ & & - & \\
\hline Sunbul 2014 & 3.2 & 0.6 & 100 & 2.6 & 0.4 & 50 & $38.5 \%$ & $0.60[0.44,0.76]$ & & 들 & \\
\hline Yilmaz 2011 & 6.4 & 1.3 & 54 & 5.4 & 1 & 56 & $34.3 \%$ & $1.00[0.57,1.89]$ & & - & \\
\hline Total $(95 \% \mathrm{Cl})$ & & & 211 & & & 136 & $100.0 \%$ & $1.17[0.45,1.89]$ & & & \\
\hline $\begin{array}{l}\text { Heterogenelty: Tau }{ }^{2} \\
\text { Test for overall effec }\end{array}$ & $\begin{array}{l}0.34 ; C \\
Z=3 .\end{array}$ & $\begin{array}{l}\mathrm{hi}^{2}= \\
20(\mathrm{P}\end{array}$ & $\begin{array}{l}17.98, \\
=0.00\end{array}$ & $\mathrm{df}=2$ & & 0001) & $1^{2}=89 \%$ & & $\begin{array}{cc}-4 & -2 \\
& \text { Favours [NAFLD] }\end{array}$ & Favours [control] & 4 \\
\hline
\end{tabular}

B

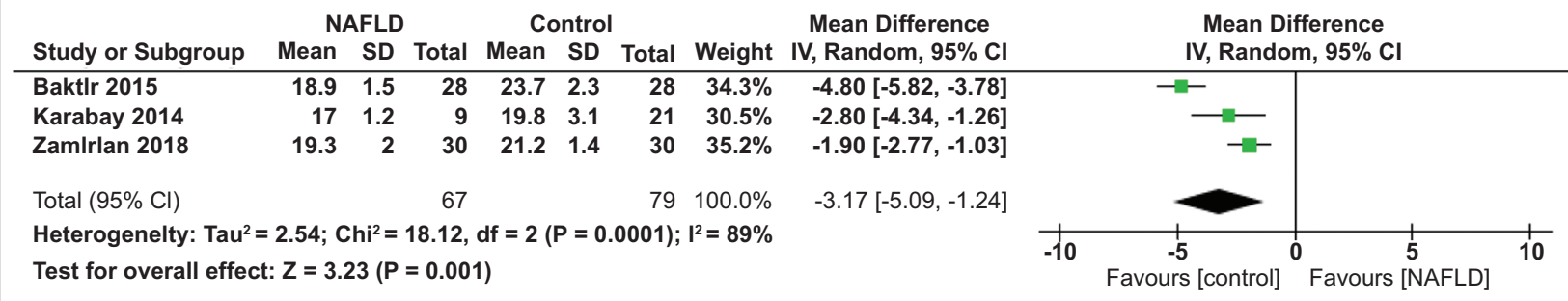

C

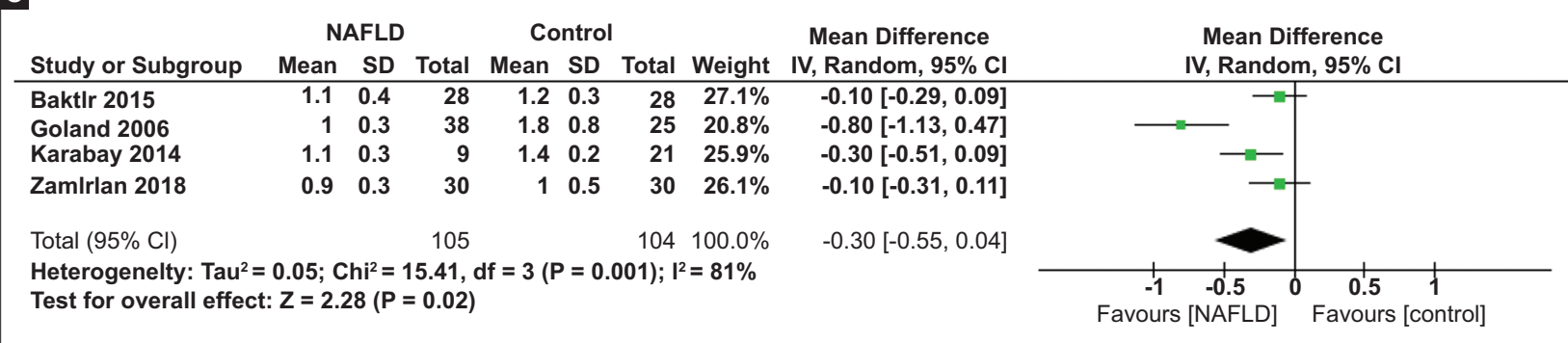

D

\begin{tabular}{|c|c|c|c|c|c|c|c|c|c|c|c|}
\hline \multirow[b]{2}{*}{ Study or Subgroup } & \multicolumn{3}{|c|}{ NAFLD } & \multicolumn{3}{|c|}{ Control } & \multirow[b]{2}{*}{ Weight } & \multirow{2}{*}{$\begin{array}{l}\text { Mean Difference } \\
\text { IV, Random, } 95 \% \mathrm{Cl}\end{array}$} & \multirow{2}{*}{\multicolumn{3}{|c|}{$\begin{array}{l}\text { Mean Difference } \\
\text { IV, Random, } 95 \% \mathrm{CI}\end{array}$}} \\
\hline & Mean & SD & Total & Mean & SD & Total & & & & & \\
\hline Baktlr 2015 & 66.7 & 5.2 & 28 & 65.7 & 2.4 & 28 & $28.6 \%$ & $1.00[-1.12,3.12]$ & & E- & \\
\hline Goland 2006 & 64.3 & 6.5 & 38 & 65.8 & 3.9 & 25 & $19.5 \%$ & $-1.50[-4.07,1.07]$ & & & \\
\hline Karabay 2014 & 62.4 & 6.5 & 9 & 62.5 & 4.5 & 21 & $5.9 \%$ & $-1.10[-4.76,4.56]$ & & & \\
\hline Sunbul 2014 & 65.2 & 6 & 100 & 66.8 & 7 & 50 & $25.0 \%$ & $-1.60[-3.87,0.67]$ & & - & \\
\hline ZamIrlan 2018 & 56.7 & 4.6 & 30 & 57.1 & 5.2 & 30 & $20.9 \%$ & $-0.40[-2.88,2.08]$ & & & \\
\hline Total $(95 \% \mathrm{Cl})$ & & & 205 & & & 154 & $100.0 \%$ & $-0.50[-1.63,0.64]$ & & & \\
\hline \multicolumn{9}{|c|}{$\begin{array}{l}\text { Heterogenelty: } \text { Tau }^{2}=0.00 ; \mathrm{Chi}^{2}=3.44, \mathrm{df}=4(P=0.49) ; \mathrm{I}^{2}=0 \% \\
\text { Test for overall effect: } Z=0.86(P=0.39)\end{array}$} & $\begin{array}{ccc}-4 & -2 & 0 \\
\text { Favours [NAFLD] }\end{array}$ & $\begin{array}{cc}1 & 2 \\
\text { Favours [ }\end{array}$ & $\begin{array}{c}4 \\
\text { [control] }\end{array}$ \\
\hline
\end{tabular}

Figure 2 Forest plots summarizing the number of studies and the differences in the examined parameters: (A) epicardial fat thickness in NAFLD patients vs. controls (mean difference [MD] 1.17, confidence interval [CI] 0.45 to 1.89, I2=89\%); (B) global longitude strain in NAFLD patients vs. controls (MD -3.17, 95\%CI -5.09 to - 1.24, $I^{2}=89 \%$ ); (C) E/A ratio in NAFLD patients vs. controls (MD -0.30, 95\%CI -0.55 to $-0.04, I^{2}=81 \%$ ); (D) left ventricular ejection fraction in NAFLD patients vs. controls (MD -0.50, 95\%CI - 1.63 to $0.64, I^{2}=0 \%$ )

NAFLD, nonalcoholic fatty liver disease; SD, standard deviation 
this conventional tool would result in missing the early stages of LV systolic dysfunction. Similarly, despite the higher EFT levels in NAFLD subjects, their mean scores fell within the accepted range. Previously Fotbolcu et al showed that LV mass index, interventricular septum and posterior wall thickness were higher in normotensive, nondiabetic NAFLD patients than in normal individuals [9]. They found significant systolic dysfunction detected by tissue Doppler imaging in NAFLD patients, although ventricular dimensions and LVEF were similar in both groups [28]. In addition, the $\mathrm{E} / \mathrm{A}$ ratio is a useful marker of $\mathrm{LV}$ diastolic function. A potential unfavorable effect of MetS and NAFLD on LV diastolic function was shown in the Strong Heart Study, where lower mitral E/A ratio values were found in patients with MetS [29].

It is widely known that in patients with NAFLD, and especially NASH and liver fibrosis, the most common cause of death is CVD [6]. Advanced fibrosis on liver histology seems to be the most important prognostic factor for CVD development [30]. However, the link between CVD and NAFLD has not yet been fully explained, although several mechanisms have been proposed. Possible mechanisms that have been incriminated as contributing to CVD pathogenesis in NAFLD patients are insulin resistance, an atherogenic lipid profile, cytokines and adipokines, impaired endothelial function, genetic predisposition, oxidative stress, low-grade systemic inflammation, hyperhomocysteinemia, and bacterial dysbiosis in the gut-liver axis [31]. The atherogenic role of hepatic inflammation is also supported by the fact that patients with NASH have a higher prevalence of atherosclerosis when compared with patients with simple steatosis [32].

According to extensive literature research, this is the first known meta-analysis to examine the connection between biopsy-proven NAFLD and subclinical cardiac damage. The main strength of our study is that the NAFLD diagnosis in the included studies was established through liver biopsy. However, our study has some limitations. Although carotid intima-media thickness represents a CVD marker, its correlation with NAFLD remains controversial and, since the study by Madan et al, there has been insufficient work investigating this relationship to justify including it in our meta-analysis. The outcomes examined in our meta-analysis showed considerable heterogeneity: specifically for EFT, GLs and E/A ratio, it was $89 \%, 89 \%$ and $81 \%$, respectively. This heterogeneity is probably due to the small number of studies that performed liver biopsy for identifying NAFLD, as well as the unknown reproducibility in the echocardiographic measurements. Conversely, the heterogeneity of LVEF was $0 \%$. Furthermore, the risk assessment of the included studies showed that the majority of them were of low quality, as only 3 studies had NOS equal to 7 (NOS values $\geq 7$, are considered as having a good/ acceptable quality); therefore, a sensitivity analysis could not be performed. It has to be noted that, in the study by Goland et al [17], NAFLD was diagnosed through liver biopsy only for a part of the patient population (11/38). However, we decided to include the study given the limited number available, and only after confirming that our results did not change, even when the related analyses were performed without this study (Supplementary Material 3, 4). Because of these limitations, a robust conclusion is yet to be reached. Therefore, it is expected that further studies with a larger representative sample of the NAFLD population would add valuable information to this important issue.
In terms of clinical practice, the results of this study suggest that subclinical cardiac damage is present in NAFLD patients. Thus, indicating that specifically, we suggest that NAFLD could be considered and tested as a potential independent risk factor for subclinical CVD development. Current guidelines propose that NAFLD patients should be checked for CVD factors [5], but do not further recommend a detailed cardiovascular screening and/or follow up for this high-risk population.

Future clinical studies should include larger numbers of patients with biopsy-proven NAFLD to confirm these findings. These studies should also focus on appraising the existence and prevalence of other CVD risk factors in NAFLD patients. In addition, it would be important to evaluate the presence of subclinical cardiac damage in patients with biopsy-proven NAFLD (5\% steatosis) compared to those diagnosed by ultrasound ( $>20-$ $30 \%$ steatosis). In this way, the existence of subclinical cardiac damage could be evaluated even in the initial and theoretically more benign stages of NAFLD. Studies assessing the costeffectiveness of subclinical cardiovascular screening in NAFLD/ NASH patients are also needed. Finally, big data population-based studies should be conducted, examining the impact of NAFLD as a marker for improving the already existing cardiovascular scores.

In conclusion, reflecting on our evidence and the abovementioned points, we think that future studies should assess the need to include subclinical cardiac damage assessment in the screening guidelines and follow up of patients with NAFLD, or at least of patients with NASH and liver fibrosis, independently of the existence of other cardiovascular risk factors. At the same time, we highlight the need for further study of the relationship between CVD and NAFLD, to reinforce the concept that NALFD could perhaps be included in the already known CVD risk scores, as an independent marker of further CVD [22-24].

\section{Summary Box}

\section{What is already known:}

- Nonalcoholic fatty liver disease (NAFLD) is a modern epidemic, affecting more than $25 \%$ of the general population worldwide

- NAFLD can be diagnosed either by ultrasound or by other radiological methods, but liver biopsy is considered to be the diagnostic gold standard

- Cardiovascular disease (CVD) is the most common cause of morbidity and mortality in NAFLD patients

\section{What the new findings are:}

- NAFLD seems to be related to subclinical cardiac damage

- We recommend the inclusion of NAFLD as an independent risk factor for CVD development

- Preventive and therapeutic interventions early in the course of NAFLD may decrease cardiovascular morbidity 


\section{References}

1. Younossi ZM, Koenig AB, Abdelatif D, Fazel Y, Henry L, Wymer M. Global epidemiology of nonalcoholic fatty liver diseaseMeta-analytic assessment of prevalence, incidence, and outcomes. Hepatology 2016;64:73-84.

2. Loomba R, Sanyal AJ. The global NAFLD epidemic. Nat Rev Gastroenterol Hepatol 2013;10:686-690.

3. Chalasani N, Younossi Z, Lavine JE, et al. The diagnosis and management of nonalcoholic fatty liver disease: practice guidance from the American Association for the Study of Liver Diseases. Hepatology 2018;67:328-357.

4. Benedict M, Zhang X. Non-alcoholic fatty liver disease: An expanded review. World J Hepatol 2017;9:715-732.

5. Marchesini G, Day C, Dufour J, et al; European Association for the Study of Obesity (EASO). EASL-EASD-EASO Clinical Practice Guidelines for the management of non-alcoholic fatty liver disease. J Hepatol 2016;64:1388-1402.

6. Söderberg C, Stål P, Askling J, et al. Decreased survival of subjects with elevated liver function tests during a 28-year follow-up. Hepatology 2010;51:595-602.

7. Petta S, Argano C, Colomba D, et al. Epicardial fat, cardiac geometry and cardiac function in patients with non-alcoholic fatty liver disease: association with the severity of liver disease. J Hepatol 2015;62:928-933.

8. Madan SA, John F, Pyrsopoulos N, Pitchumoni CS. Nonalcoholic fatty liver disease and carotid artery atherosclerosis in children and adults: a meta-analysis. Eur J Gastroenterol Hepatol 2015;27:12371248.

9. Fotbolcu H, Yakar T, Duman D, et al. Aortic elastic properties in nonalcoholic fatty liver disease. Blood Press Monit 2010;15:139145.

10. Mantovani A, Zoppini G, Targher G, Golia G, Bonora E. Nonalcoholic fatty liver disease is independently associated with left ventricular hypertrophy in hypertensive Type 2 diabetic individuals. J Endocrinol Invest 2012;35:215-218.

11. Kim NH, Park J, Kim SH, et al. Non-alcoholic fatty liver disease, metabolic syndrome and subclinical cardiovascular changes in the general population. Heart 2014;100:938-943.

12. Iacobellis G, Ribaudo MC, Assael F, et al. Echocardiographic epicardial adipose tissue is related to anthropometric and clinical parameters of metabolic syndrome: a new indicator of cardiovascular risk. J Clin Endocrinol Metab 2003;88:5163-5168.

13. Iacobellis G, Assael F, Ribaudo MC, et al. Epicardial fat from echocardiography: a new method for visceral adipose tissue prediction. Obes Res 2003;11:304-310.

14. Malavazos AE, Di Leo G, Secchi F, et al. Relation of echocardiographic epicardial fat thickness and myocardial fat. Am J Cardiol 2010;105:1831-1835.

15. Iacobellis G, Bianco AC. Epicardial adipose tissue: emerging physiological, pathophysiological and clinical features. Trends Endocrinol Metab 2011;22:450-457.

16. Zamirian M, Samiee E, Moaref A, Abtahi F, Tahamtan M. Assessment of subclinical myocardial changes in non-alcoholic fatty liver disease: a case-control study using speckle tracking echocardiography. Iran J Med Sci 2018;43:466-472.
17. Goland S, Shimoni S, Zornitzki T, et al. Cardiac abnormalities as a new manifestation of nonalcoholic fatty liver disease: echocardiographic and tissue Doppler imaging assessment. J Clin Gastroenterol 2006;40:949-955.

18. Pacifico L, Di Martino M, De Merulis A, et al. Left ventricular dysfunction in obese children and adolescents with nonalcoholic fatty liver disease. Hepatology 2014;59:461-470.

19. Sert A, Pirgon O, Aypar E, Yilmaz H, Odabas D. Relationship between left ventricular mass and carotid intima media thickness in obese adolescents with non-alcoholic fatty liver disease. J Pediatr Endocrinol Metab 2012;25:927-934.

20. Moher D, Liberati A, Tetzlaff J, Altman DG; PRISMA Group. Preferred reporting items for systematic reviews and metaanalyses: the PRISMA statement. PLoS Med 2009;6:e1000097.

21. SB WG, D OC, J P, et al. The Newcastle-Ottawa Scale (NOS) for assessing the quality of nonrandomised studies in meta-analyses. 2013. Available from: http://www.ohri.ca/programs/clinical_ epidemiology/oxford.asp [Accessed 14 December 2020].

22. Colak Y, Karabay CY, Tuncer I, et al. Relation of epicardial adipose tissue and carotid intima-media thickness in patients with nonalcoholic fatty liver disease. Eur J Gastroenterol Hepatol 2012;24:613-618.

23. Sunbul M, Agirbasli M, Durmus E, et al. Arterial stiffness in patients with non-alcoholic fatty liver disease is related to fibrosis stage and epicardial adipose tissue thickness. Atherosclerosis 2014;237:490-493.

24. Yilmaz Y, Kurt R, Gurdal A, et al. Circulating vaspin levels and epicardial adipose tissue thickness are associated with impaired coronary flow reserve in patients with nonalcoholic fatty liver disease. Atherosclerosis 2011;217:125-129.

25. Baktır AO, Şarlı B, Altekin RE, et al. Non alcoholic steatohepatitis is associated with subclinical impairment in left ventricular function measured by speckle tracking echocardiography. Anatol J Cardiol 2015; 15:137-142.

26. Karabay CY, Kocabay G, Kalayci A, et al. Impaired left ventricular mechanics in nonalcoholic fatty liver disease: a speckle-tracking echocardiography study. Eur J Gastroenterol Hepatol 2014;26:325331.

27. Saadeh S, Younossi ZM, Remer EM, et al. The utility of radiological imaging in nonalcoholic fatty liver disease. Gastroenterology 2002;123:745-750.

28. Fotbolcu H, Yakar T, Duman D, et al. Impairment of the left ventricular systolic and diastolic function in patients with nonalcoholic fatty liver disease. Cardiol J 2010;17:457-463.

29. Chinali M, Devereux RB, Howard BV, et al. Comparison of cardiac structure and function in American Indians with and without the metabolic syndrome (the Strong Heart Study). Am J Cardiol 2004;93:40-44

30. Targher G, Day CP, Bonora E. Risk of cardiovascular disease in patients with nonalcoholic fatty liver disease. $N$ Engl $\mathrm{J}$ Med 2010;363:1341-1350.

31. Francque SM, van der Graaff D, Kwanten WJ. Non-alcoholic fatty liver disease and cardiovascular risk: pathophysiological mechanisms and implications. J Hepatol 2016;65:425-443.

32. Ekstedt M, Franzén LE, Mathiesen UL, et al. Long-term follow-up of patients with NAFLD and elevated liver enzymes. Hepatology 2006;44:865-873. 


\section{Supplementary material}

Supplementary Material 1 Medline and Central search strategies

9 April 2020, 21:00

MEDLINE search strategy

via PubMed

\#1

1. non-alcoholic fatty liver disease (17417)

2. NAFLD (20051)

3. fatty liver (79717)

4. hepatic steatosis (83085)

5. nonalcoholic steatohepatitis (19717)

6. 1 or 2 or 3 or 4 or 5 (84112)

7. left ventricular mass (22965)

8. left ventricular hypertrophy (31564)

9. echocardiography (178249)

10. ventricular dysfunction (69898)

11.7 or 8 or 9 or 10 (244955)

12.6 and $11(285)$

\#2

(“Non-alcoholic Fatty Liver Disease”[Mesh]) AND “Hypertrophy, Left Ventricular”[Mesh] (8)

\section{CENTRAL search strategy}

\#1: Non-alcoholic Fatty Liver Disease:ti,ab,kw (Word variations have been searched) (1635: 9 Cochrane Reviews, 3 Cochrane Protocols, 1623 Trials)

\#2: left ventricular:ti,ab,kw (Word variations have been searched) (17339: 31 Cochrane Reviews, 1 Cochrane Protocols, 17307 Trials,)

\#3: \#1 and \#2 (2: 2Trials) 
Supplementary Material 2 MOOSE checklist for meta-analyses of observational studies

\begin{tabular}{|c|c|c|c|}
\hline \# & MOOSE Checklist & $\begin{array}{l}\text { Completed } \\
\text { (Y/N/NA) }\end{array}$ & Pages \\
\hline 1 & Title: Identify the study as a meta-analysis (or systematic review) & $\mathrm{Y}$ & 1 \\
\hline 2 & Abstract: Use the journal's structured format & $\mathrm{Y}$ & 4 \\
\hline 3 & Introduction Present: The clinical problem & $\mathrm{Y}$ & 6 \\
\hline 4 & Introduction Present: The hypothesis & $\mathrm{Y}$ & 7 \\
\hline 5 & $\begin{array}{l}\text { Introduction Present: A statement of objectives that includes the study population, the } \\
\text { condition of interest, the exposure or intervention, and the outcome(s) considered }\end{array}$ & $\mathrm{Y}$ & 7 \\
\hline 6 & Sources Describe: Qualifications of searchers (e.g., librarians and investigators) & $\Upsilon$ & 8 \\
\hline 7 & $\begin{array}{l}\text { Sources Describe: Search strategy, including time period included in the synthesis and } \\
\text { keywords }\end{array}$ & $\mathrm{Y}$ & 8 \\
\hline 8 & Sources Describe: Effort to include all available studies, including contact with authors & $\mathrm{Y}$ & $7-8$ \\
\hline 9 & Sources Describe: Databases and registries searched & $\mathrm{Y}$ & $7-8$ \\
\hline 10 & $\begin{array}{l}\text { Sources Describe: Search software used, name and version, including special features } \\
\text { used (e.g., explosion) }\end{array}$ & $\mathrm{Y}$ & 8 \\
\hline 11 & Sources Describe: Use of hand searching (e.g., reference lists of obtained articles) & $\Upsilon$ & 8 \\
\hline 12 & Sources Describe: List of citations located and those excluded, including justification & $\mathrm{Y}$ & 8 \\
\hline 13 & Sources Describe: Method of addressing articles published in languages other than English & $\mathrm{Y}$ & 8 \\
\hline 14 & Sources Describe: Method of handling abstracts and unpublished studies & $\mathrm{Y}$ & 8 \\
\hline 15 & Sources Describe: Description of any contact with authors & $\mathrm{Y}$ & $\begin{array}{l}\text { 7-8 No contacts. All documents } \\
\text { were available online }\end{array}$ \\
\hline 16 & Study Selection Describe: Types of study designs considered & $\mathrm{Y}$ & 8 \\
\hline 17 & $\begin{array}{l}\text { Study Selection Describe: Relevance or appropriateness of studies gathered for } \\
\text { assessing the hypothesis to be tested }\end{array}$ & $\mathrm{Y}$ & 8 \\
\hline 18 & $\begin{array}{l}\text { Study Selection Describe: Rationale for the selection and coding of data (e.g., sound } \\
\text { clinical principles or convenience) }\end{array}$ & $\mathrm{Y}$ & 9 \\
\hline 19 & $\begin{array}{l}\text { Study Selection Describe: Documentation of how data were classified and coded (e.g., } \\
\text { multiple raters, blinding, and interrater reliability) }\end{array}$ & $\mathrm{Y}$ & 9 \\
\hline 20 & $\begin{array}{l}\text { Study Selection Describe: Assessment of confounding (e.g., comparability of cases and } \\
\text { controls in studies where appropriate }\end{array}$ & $\mathrm{Y}$ & 9 \\
\hline 21 & $\begin{array}{l}\text { Study Selection Describe: Assessment of study quality, including blinding of quality } \\
\text { assessors; stratification or regression on possible predictors of study results }\end{array}$ & $\mathrm{Y}$ & 9 \\
\hline 22 & Study Selection Describe: Assessment of heterogeneity & $\mathrm{Y}$ & 9 \\
\hline 23 & $\begin{array}{l}\text { Study Selection Describe: Statistical methods (e.g., complete description of fixed } \\
\text { or random effects models, justification of whether the chosen models account for } \\
\text { predictors of study results, dose-response models, or cumulative meta-analysis) in } \\
\text { sufficient detail to be replicated }\end{array}$ & $\mathrm{Y}$ & 9 \\
\hline 24 & Results Present: A graph summarizing individual study estimates and the overall estimate & $\mathrm{Y}$ & $10-11$ \\
\hline 25 & Results Present: A table giving descriptive information for each included study & $\mathrm{Y}$ & 10 \\
\hline 26 & Results Present: Results of sensitivity testing (e.g., subgroup analysis) & NA & 13 \\
\hline 27 & Results Present: Indication of statistical uncertainty of findings & $\mathrm{Y}$ & $10-11$ \\
\hline 28 & Discussion Discuss: Strengths and weaknesses & $\mathrm{Y}$ & $12-13$ \\
\hline 29 & Discussion Discuss: Potential biases in the review process (e.g., publication bias) & $\mathrm{N}$ & small number of studies \\
\hline 30 & $\begin{array}{l}\text { Discussion Discuss: Justification for exclusion (e.g., exclusion of non-English-language } \\
\text { citations) }\end{array}$ & $\mathrm{Y}$ & 9 \\
\hline 31 & Discussion Discuss: Assessment of quality of included studies & $\mathrm{Y}$ & 9 \\
\hline 32 & Discussion Discuss: Consideration of alternative explanations for observed results & $\mathrm{Y}$ & $12-13$ \\
\hline 33 & $\begin{array}{l}\text { Discussion Discuss: Generalization of the conclusions (i.e., appropriate for the data } \\
\text { presented and within the domain of the literature review) }\end{array}$ & $\mathrm{Y}$ & 13 \\
\hline 34 & Discussion Discuss: Guidelines for future research & $\mathrm{Y}$ & $13-14$ \\
\hline 35 & Discussion Discuss: Disclosure of funding source & $\mathrm{Y}$ & 2 \\
\hline
\end{tabular}




\begin{tabular}{|c|c|c|c|c|c|c|c|c|c|}
\hline \multirow[b]{2}{*}{ Study or Subgroup } & \multicolumn{3}{|c|}{ NAFLD } & \multicolumn{2}{|c|}{ Control } & \multirow[b]{2}{*}{ Total } & \multirow[b]{2}{*}{ Weight } & \multirow{2}{*}{$\begin{array}{l}\text { Mean Difference } \\
\text { IV, Random, } 95 \% \mathrm{CI}\end{array}$} & \multirow{2}{*}{$\begin{array}{l}\text { Mean Difference } \\
\text { IV, Random, } 95 \% \mathrm{CI}\end{array}$} \\
\hline & Mean & SD & Total & Mean & SD & & & & \\
\hline Baktlr 2015 & 1.1 & 0.4 & 28 & 1.2 & 0.3 & 28 & $38.4 \%$ & $-0.10[-0.29,0.09]$ & $\rightarrow+$ \\
\hline Goland 2006 & 1 & 0.3 & 38 & 1.8 & 0.8 & 25 & & Not estimable & \\
\hline Karabay 2014 & 1.1 & 0.3 & 9 & 1.4 & 0.2 & 21 & $30.2 \%$ & $-0.30[-0.51,0.09]$ & 一— \\
\hline ZamIrlan 2018 & 0.9 & 0.3 & 30 & 1 & 0.5 & 30 & $31.4 \%$ & $-0.10[-0.31,0.11]$ & 一ㄴ- \\
\hline Total $(95 \% \mathrm{Cl})$ & & & 67 & & & 79 & $100.0 \%$ & $-0.16[-0.29,-0.03]$ & \\
\hline \multicolumn{9}{|c|}{$\begin{array}{l}\text { Heterogenelty: } \mathrm{Tau}^{2}=0.00 ; \mathrm{Chi}^{2}=2.37, \mathrm{df}=2(\mathrm{P}=0.31) ; \mathrm{I}^{2}=16 \% \\
\text { Test for overall effect: } Z=2.48(P=0.01)\end{array}$} & $\begin{array}{ccccc}-1 & -0.5 & 0 & 0.5 & 1 \\
& & 0.5 \\
\text { Favours [NAFLD] } & \text { Favours [control] }\end{array}$ \\
\hline
\end{tabular}

Supplementary Material 3 Forest plot summarizing the 3 studies (without Goland et al [17]) with respect to the difference in E/A ratio between NAFLD patients and controls (mean difference -0.16 , confidence interval [CI] -0.29 to $-0.03, I^{2}=16 \%$ )

E/A ratio, ratio between diastolic early-and late-diastolic mitral inflow velocities; NAFLD, nonalcoholic fatty liver disease; SD, standard deviation

\begin{tabular}{|c|c|c|c|c|c|c|c|c|c|}
\hline \multirow[b]{2}{*}{ Study or Subgroup } & \multicolumn{2}{|c|}{ NAFLD } & \multicolumn{3}{|c|}{ Control } & \multirow[b]{2}{*}{ Total } & \multirow[b]{2}{*}{ Weight } & \multirow{2}{*}{$\begin{array}{c}\text { Mean Difference } \\
\text { IV, Random, } 95 \% \mathrm{CI}\end{array}$} & \multirow{2}{*}{$\begin{array}{c}\text { Mean Difference } \\
\text { IV, Random, } 95 \% \mathrm{CI}\end{array}$} \\
\hline & Mean & SD & Total & Mean & SD & & & & \\
\hline Baktır 2015 & 66.7 & 5.2 & 28 & 65.7 & 2.4 & 28 & $35.6 \%$ & $1.00[-1.12,3.12]$ & F- \\
\hline Goland 2006 & 64.3 & 6.5 & 38 & 65.8 & 3.9 & 25 & $0.0 \%$ & $-1.50[-4.07,1.07]$ & \\
\hline Karabay 2014 & 62.4 & 6.5 & 9 & 62.5 & 4.5 & 21 & $7.4 \%$ & $-0.10[-4.76,4.56]$ & \\
\hline Sunbul 2014 & 65.2 & 6 & 100 & 66.8 & 7 & 50 & $31.1 \%$ & $-1.60[-3.87,0.67]$ & - \\
\hline ZamIrlan 2018 & 56.7 & 4.6 & 30 & 57.1 & 5.2 & 30 & $25.9 \%$ & $-1.40[-2.88,2.08]$ & \\
\hline Total $(95 \% \mathrm{Cl})$ & & & 167 & & & 129 & $100.0 \%$ & $-0.25[-1.52,1.01]$ & \\
\hline \multicolumn{9}{|c|}{$\begin{array}{l}\text { Heterogenelty: } \text { Tau}^{2}=0.00 ; \mathrm{Chi}^{2}=2.71, \mathrm{df}=3(\mathrm{P}=0.44) ; \mathrm{I}^{2}=0 \% \\
\text { Test for overall effect: } \mathrm{Z}=0.39(\mathrm{P}=0.70)\end{array}$} & 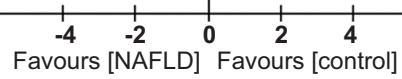 \\
\hline
\end{tabular}

Supplementary Material 4 Forest plot summarizing the 4 studies (without Goland et al) with respect to the difference in left ventricular ejection fraction between NAFLD patients and controls (mean difference -0.25 , confidence interval $[\mathrm{CI}]=-1.52$ to $1.01, I^{2}=0 \%$ )

NAFLD, nonalcoholic fatty liver disease; SD, standard deviation 